\title{
O CONCEITO DE SUJEITO NOS ANTECEDENTES LACANIANOS: UMA LEITURA EM NACHTRÄGLICHKEIT
}

\section{ERIKSON KASZUBOWSKI}

\section{Erikson Kaszubowski}

Universidade Federal de Santa Catarina (UFSC), doutor em Psicologia pelo Programa de PósGraduação em Psicologia e psicólogo do Serviço de Atenção Psicológica, Florianópolis/SC, Brasil.
RESUMO: Examino, por meio de uma leitura fundada no conceito de Nachträglichkeit, o movimento do pensamento de Lacan a partir de seus escritos antecedentes até o momento em que formaliza a função do sujeito, com o objetivo de identificar os fios discursivos que impelem Lacan em direção a esse conceito. Tal movimento retrospectivo permite verificar o quanto dois dos principais predicados do sujeito - o fato de ele ser causado no campo do Outro e de manter um índice de indeterminação impossível de ser objetivado estão presentes nos questionamentos de Lacan pelo menos desde sua tese de doutorado.

Palavras-chave: sujeito; estruturalismo; leitura retroativa; Nachträglichkeit.

\begin{abstract}
The question of the subject in Lacan's antecedents: a Nachträglichkeit reading. I follow Lacan's thoughts from his antecedent essays to the moment that he formalizes the function of the subject, reading those texts with the help of the concept of Nachträglichkeit, with the objective of unraveling the discursive threads that propel Lacan in the direction of the concept of subject. This retrospective movement shows that two of the most important predicates of the subject - the fact that the subject is caused in the field of the Other, and yet the subject maintains a indetermination that is impossible to be objectified - are present at least since Lacan's doctorate thesis.
\end{abstract} Keywords: subject; structuralism; retroactive reading; Nachträglichkeit.

DOI - http://dx.doi.org/10.1590/1809-44142018001010 


\section{INTRODUÇÃO}

Por que chamar de sujeito o inconsciente estruturado como uma linguagem? Ainda que um exame pormenorizado não permita identificar completamente o inconsciente ao sujeito, a questão não é ingênua: Lacan (1968/2006) afirma ter sido por ela interpelado, e o autor da indagação teve seu nome esquecido. Este escrito propõe retomar essa questão na procura da emergência do conceito de sujeito na psicanálise lacaniana.

Afora uma menção passageira - ainda que importante (CABAS, 2009) - no artigo Pulsões e destinos da pulsão, o conceito de sujeito não está presente na obra freudiana. É Lacan quem o introduz e o formaliza na psicanálise. Porém, o que leva Lacan a tomar um conceito arraigado na metafísica para conformar um aspecto fundamental de sua doutrina? E mais: como ele formaliza este conceito num período em que seu ensino se encontra influenciado pelo estruturalismo, movimento intelectual no qual o sujeito moderno é desconstruído?

Para que essas perguntas possam ser respondidas, é necessário examinar o movimento do pensamento de Lacan a partir de seus escritos antecedentes (LACAN, 1966/1998a) até o momento em que conceitua a primazia do registro simbólico na constituição da subjetividade e formaliza a função do sujeito (ZAFIROPOULOS, 2008). Contudo, uma leitura linear não basta; é necessário, depois de percorrer os textos na ordem cronológica, voltar aos seus inícios para ali encontrar, a posteriori, nachträglich, o conceito de sujeito em seu estado nascente, e, com isso, desembaraçar os fios discursivos que impelem Lacan em direção a esse termo.

Essa leitura, portanto, utilizará como categoria instrumental a noção de Nachträglichkeit, inicialmente concebida no contexto do Projeto para uma psicologia científica (FREUD, 1895/1990) como a temporalidade retroativa da constituição do trauma, e posteriormente retomada por Lacan para abordar a articulação significante e sua determinação na cadeia do significado pelo grafo do ponto de basta (LACAN, 19551956/1985a). Assim como só é possível falar sobre a significação de uma oração, diacronicamente organizada, num movimento de retorno da escansão sobre os primeiros elementos, também propomos reler os escritos antecedentes aos seminários como o início de um enunciado que encontrará, nos desenvolvimentos posteriores a 1953, uma primeira escansão.

Nossa proposta se alinha, portanto, ao programa exposto por Laplanche (1981) logo na abertura de seu Problematiques. Primeiramente, tomando a temporalidade própria à psicanálise como referência para a leitura da teoria analítica, focando, como também propõe Laplanche, na noção de après-coup. A utilização dessa noção fica condicionada, por sua vez, a uma leitura que aplique aos textos o aplatissement típico de uma sessão analítica. Com isso, a relevância e significado dos textos lidos permanecem em suspenso até que um elemento significante permita retomá-los sob uma nova luz - interpretá-los, no sentido psicanalítico.

\section{AS LEIS EVOLUTIVAS DA PERSONALIDADE}

As ocorrências do termo sujeito nos primeiros textos de Lacan não parecem obedecer a nenhum rigor conceitual. Em seu lugar, recorre à formulação de um conceito para abarcar as diversas instâncias psíquicas tal como a noção de aparelho psíquico em Freud - sob o nome de personalidade. Tal desenvolvimento, entretanto, fica restrito à sua tese (LACAN, 1932/2000).

Lacan indica que os predicativos da personalidade no conhecimento comum são: sua síntese - na medida em que promoveria o sentimento de unidade do sujeito; sua intencionalidade - por se orientar em direção ao futuro; e sua responsabilidade - pois situa o ponto de ancoragem da origem dos atos de um sujeito. Tais atributos, porém, não se sustentam: a experiência cotidiana é marcada por uma série de lacunas que destroem qualquer concepção unitária da personalidade, na medida em que essa pretensa unidade é interpelada por fenômenos lacunares cujas origens escapam à consciência. 
A personalidade, portanto, não pode ser considerada unitária; pelo contrário, ela é marcada por sua divisão, um "laço sempre pronto a romper-se" (LACAN, 1932/2000, s/p). Lacan atribui essa esquize na personalidade à distância que separa o "eu real" do "ideal que o orienta". Esse exame da personalidade a coloca em proximidade com o que é posteriormente desenvolvido por Lacan na noção de um sujeito dividido: uma noção totalizante de personalidade não dá conta dos fenômenos concretos do psiquismo, o que torna necessário postular uma divergência mínima, mesmo que primeiramente centrada na diferença entre o aspecto concreto da personalidade e os ideais que a movimentam.

Ainda assim, Lacan procura por uma unidade da personalidade, e a encontra num exame objetivo de sua constituição: a personalidade obedece a um desenvolvimento geral, de acordo com leis que podem ser generalizadas. No lugar de uma síntese subjetiva, demonstrada ser impossível pelos fenômenos lacunares, encontra-se uma lei evolutiva. Se essas leis possibilitam uma visada objetiva acerca da personalidade, também a fazem subsumir no determinismo. Em função disso, torna-se necessário explicar como essa personalidade chega a poder dizer eu de si e atribuir a esse eu a intencionalidade de suas ações.

O paradoxo entre determinação e atividade, tema recorrente nos seminários de Lacan, apresenta-se, portanto, já na alvorada de suas elaborações teóricas. A determinação subjetiva ainda não é tributária da racionalidade estrutural, mas as leis evolutivas não estão submetidas ao orgânico. Pelo contrário: ao serem abordadas no escrito de 1938 sobre os complexos familiares (LACAN, 1938/1985b), elas são descritas como eminentemente sociais. E ainda que essa determinação social se avolume, deixando pouco espaço para se pensar numa subjetividade intencional, Lacan (1963-1964/1998j) fará questão de marcar seu lugar, anos mais tarde, ao preservar o termo sujeito para falar desse encontro entre um corpo vivente e o campo do Outro, demonstrando aí persistir um resto de subjetividade que resiste à determinação completa ao significante. Ou, retomando a forma como ele se expressa em sua tese, a personalidade pode se afirmar num eu para além de suas determinações objetivas.

As premissas desenvolvidas na tese pontuam a orientação do pensamento de Lacan. Primeiramente, o interesse da fundação de uma disciplina científica sobre a subjetividade que não se perdesse na metafísica e nem reduzisse o psiquismo a um epifenômeno das reações do organismo. Portanto, não é à toa que Lacan critica a possibilidade de se falar acerca da personalidade a partir de um viés introspectivo. Pelo contrário, é necessário ressaltar aquilo que da personalidade pode ser efetivamente objetivado, e tal objetividade é conseguida através do estudo das leis que operam o desenvolvimento universal da personalidade. Só assim seria possível entrever um campo de conhecimento que pudesse aspirar a ser uma ciência da personalidade. Esse campo objetivo, passível de ser enunciado em leis, será tomado de empréstimo das ciências sociais, como primeiramente pontuado na tese e posteriormente desenvolvido no artigo sobre os complexos familiares. Logo, o sujeito que pode ser preliminarmente lido sob o conceito de personalidade é caracterizado por uma determinação de si que é objetiva e não lhe pertence totalmente, por estar situada no campo das relações sociais.

\section{ATIVIDADE E SOBREDETERMINAÇÃO}

Mesmo assim, é ao termo sujeito, nos escritos antecedentes, que se alinham adjetivos relativos à atividade. No escrito de 1936, Para-além do "princípio de realidade", a noção de sujeito vem seguida de seu papel ativo na organização dos estímulos perceptivos, tal como descobrem os experimentos gestálticos: "dos fatos experimentais em que se manifesta a atividade do sujeito na organização da forma" (LACAN, $1936 / 1998$ b, p. 79). Este texto retoma a personalidade como conceito fundamental para se pensar o psiquismo, antecipando a importância dos conceitos de imago, complexo e identificação como fundamentais na sua constituição. A noção de complexo pontua como se dá a inserção dessa ordem exterior, o social, na constituição do sujeito. A identificação, por outro lado, marca esse pequeno grau de atividade do sujeito, na medida em que comporta uma ação específica, mesmo que na direção de sua alienação nas imagos 
primordiais estruturadas pelo complexo. A identificação, assim colocada, transmite "os traços que, no indivíduo, dão a forma particular de suas relações humanas, ou dito de outra maneira, de sua personalidade" (LACAN, 1936/1998b, p. 92).

Se as noções de complexo e de identificação permitem a Lacan melhor situar o paradoxo da determinação e da atividade do sujeito, antecipando, ainda que com grande diferença, a estruturação do sujeito no campo do Outro, fica evidente, já neste escrito de 1936, um ponto nodal que põe todo o jogo das identificações em causa. O que move o sujeito na identificação com essa série de complexos é a insuficiência vital que constitui a experiência primordial do infans, já denominada por Freud (1900/2001) de desamparo (Hilflosigkeit). Ora, o desamparo e a fetalização são os avatares tomados da biologia por Lacan para fazer referência à negatividade primordial que é o sujeito, enquanto sujeito do desejo. Todo movimento de identificação ao complexo e a dialética com o outro são mobilizados por uma moção de negação dessa condição primordial - a negação de uma negatividade, na medida em que é a partir da inexistência de um imaginário inato, no vazio do instinto, que o sujeito deve recorrer ao outro para se fazer conhecer e se reconhecer.

Lacan (1936/1998b) finaliza este artigo com uma pergunta indicadora de seus interesses. Numa reincidência da questão colocada na tese acerca da intencionalidade aparente do eu frente à sua sobredeterminação, pergunta-se como as identificações do sujeito constituem seu eu (Je), e onde ele se reconhece. Ainda que a questão permaneça sem resposta, já é possível verificar uma diferenciação entre o eu e sujeito: se é o sujeito que se identifica, o eu resta como um efeito dessa identificação. E mais: se é necessário perguntar pelo lugar onde o eu se reconhece, é porque ele não se reconhece nem nessa instância ativa que promove a identificação - aqui já denominada, sem muito rigor, de sujeito - nem no objeto com o qual se identifica no complexo.

Esse sujeito é mais propriamente chamado de indivíduo no escrito seguinte, Os complexos familiares na formação do indivíduo, de 1938. Ainda que o conceito de personalidade não desapareça completamente da pena de Lacan, não é mais reiterado de forma conceitual. Porém, tampouco é definida com mais precisão essa função enunciada no título, o indivíduo, que é abordado em sua relação com os complexos que o constituem. Lacan articula aos complexos o que ele anteriormente denominou as leis de desenvolvimento da personalidade, universais, na medida em que dizem respeito a situações concretas de interação social às quais o sujeito não pode se furtar de participar.

O teor da discussão feita por Lacan sobre o conceito de família traz à tona uma clara influência sociológica, e é impossível deixar de notar um tom antecipatório do estruturalismo vindouro na maneira como a organização familiar é abordada e fundamentada. Entretanto, se a ordem do indivíduo é definida apenas por sua determinação desses vários complexos oriundos do social, esse mesmo social só pode ser entendido, neste momento, como relação entre indivíduos concretos. Por isso, a redução do social às relações entre indivíduos não alcança ainda o grau propriamente simbólico da estrutura, formado por posições vazias e diferenciais.

Assim como o sujeito só pode ser definido por Lacan por sua relação de determinação ao significante ao ponto de se confundir, em seus primeiros seminários, com o próprio signo (LACAN, 1954-1955/1985c) também esse indivíduo do qual fala só pode ser abordado de forma indireta, pelos complexos que o causam. Isso porque reside no fundo das relações sociais concretas esse dado fundamental da vida humana que é sua derrelicção primordial (se partimos das influências heideggerianas), seu desamparo (se retomamos o texto freudiano) ou sua fetalização (se nos atemos às referências biológicas). Essa série de referências é subsumida, neste escrito de 1938, sob o conceito da imago do corpo despedaçado como principal agente mobilizador das identificações. Contudo, as identificações se orientam na direção da negação e não do reconhecimento dessa imago. As identificações, portanto, se apoiam sobre um ponto que não pode ser completamente subsumido em imago alguma. 
Um exemplo de movimento de resistência ao corpo despedaçado pode ser verificado no complexo de intrusão. Nesse complexo, Lacan localiza o momento no qual o sujeito se identifica como sendo um eu, naquilo que ele já denomina de estádio do espelho. $\mathrm{O}$ eu é caracterizado não como um movimento de conhecimento de si, mas, pelo contrário, de desconhecimento. Primeiro, o sujeito reconhece a si mesmo na imagem alheia; e, segundo, denega sua própria origem no outro, fazendo-se parecer autoengendrado.

A psicologia clássica se enganava, portanto, acreditando que o eu, a saber, esse objeto no qual o sujeito se reflete como coordenado à realidade que ele reconhece como exterior a si mesmo, compreende a totalidade das relações que determinam o psiquismo do sujeito. (LACAN, 1938/1985b, p. 77)

O sujeito, aqui, já aparece como algo que se encontra para além do eu, distinto deste, e que serve de índice para demarcar as falhas na completude da imagem do eu. Esse sujeito se mostra a partir de sua divisão pelo sintoma. "O sintoma neurótico representa no sujeito um momento de sua experiência em que ele não sabe se reconhecer, uma forma de divisão de sua personalidade" (LACAN, 1938/1985b, p. 76). Encontramos aqui o sujeito formulado a partir da divisão, que se mostrará, mais tarde, como fundamental na teoria lacaniana. O sujeito, o mesmo que apresenta o sintoma e deseja se livrar dele, opõe-se à cura através de variadas resistências - e é, portanto, no sintoma que o sujeito pode ser compreendido como dividido. $\mathrm{O}$ eu do sujeito não se reconhece no sintoma, dando mostras de querer se livrar dele, e, ao mesmo tempo, procura mantê-lo.

Mas, a despeito dessa submissão à dimensão social, é a atividade que serve de predicado ao sujeito nos escritos antecedentes, e ela aparece aqui com uma definição interessante quando Lacan aborda o complexo de desmame:

Pela primeira vez, parece, uma tensão vital se resolve em intenção mental. Por esta intenção, o desmame é aceito ou recusado. A intenção certamente é bastante elementar, uma vez que nem mesmo pode ser atribuída a um eu ainda no estado de rudimento. A aceitação ou a recusa não podem ser concebidas como uma escolha, uma vez que, na ausência de um eu que afirma ou nega, elas não são contraditórias: pólos coexistentes e contrários, elas determinam uma atitude ambivalente por essência, ainda que uma delas prevaleça. (LACAN, $1938 / 1985 b$, p. 24, grifo nosso)

Ou seja: o complexo coloca em jogo uma determinada tensão vital, um ponto crucial para a própria sobrevivência do infans. Seu desamparo só pode ser remediado, parcialmente, pela ação de um outro (Nebenmensch freudiano) ao qual o pequeno assujeito está completamente submetido. Nesse ponto determinante, da presença e da ausência dessa imago que é o seio, Lacan localiza uma intenção, uma ação por parte desse sujeito primitivo ao aceitar e/ou recusar (lembremos que tal ato intencional é ambivalente, contudo ato) o desmame. O que significa que, por mais determinantes que sejam os complexos na formação do indivíduo, não é possível fazer os primeiros darem conta de tudo que é referente ao segundo, permanecendo ainda um ponto mínimo de negatividade intencional. Negatividade que só pode ser evidenciada quando posta em relação a algo: por isso, a possibilidade de se abordar o sujeito somente a partir do complexo, pois é em relação a este que a negatividade pode reagir enquanto intenção.

\section{ENSAIOS PRELIMINARES DE UMA LÓGICA SUBJETIVA}

Pouco tempo mais tarde, em 1945, num dos textos antecedentes mais retomado por Lacan (1945/1998c) ao longo dos primeiros seminários, $O$ tempo lógico e a asserção da certeza antecipada, o conceito de sujeito é formulado; e mesmo que não seja propriamente conceituado, o escrito faz entrever aspectos cruciais da determinação do sujeito nos níveis imaginário e simbólico, mesmo que esses registros não tenham ainda sido batizados.

Não parece tão estranho se remetermos esse texto a uma nota de rodapé do escrito seguinte, de 1946, O número treze e a forma lógica da suspeita. Nesse artigo, Lacan (1946/2009) afirma que ambos os artigos 
detêm um propósito semelhante: uma investigação, mesmo que de natureza ensaística e a partir de modelos da lógica e da matemática recreacional, para delimitar uma lógica coletiva. Ou seja, uma lógica que pudesse dar conta das relações entre um conjunto e seus elementos, delimitando as operações de sua especificação.

A ordem coletiva, o conjunto, está dada de antemão a qualquer definição de uma singularidade, de um sujeito; tal qual a estrutura simbólica, a ordem do significante já está em jogo há muito tempo antes de entrar nela um sujeito particular. Depois, há um movimento, passível de ser organizado de forma lógica, através do qual o coletivo possibilita a diferenciação de um elemento como singular; o que implica pensar a lógica a partir da qual um sujeito se constitui a partir do campo do Outro. Isso define o caráter paradoxal desse elemento particular: tal elemento, ao mesmo tempo, pertence ao grupo, na medida em que é a partir dele que emerge, e fica posto de fora do conjunto, pois esse movimento de sua determinação ocasiona sua especificação, diferenciando-o. Lacan é explícito ao afirmar:

Essa concepção [de uma lógica] se desenvolve em uma lógica do sujeito, que nosso outro estudo faz claramente perceber, dado que viemos em seu fim tentar formular um silogismo subjetivo, pelo qual o sujeito da existência assimila-se à essência, radicalmente cultural para nós, à qual se aplica o termo humanidade. (LACAN, 1946/2009, p. 1, grifo nosso)

Se até então faltava ao sujeito ter seu lugar propriamente marcado na teoria, dessa forma tímida, numa nota de rodapé, Lacan pontua sua importância, imediatamente associando-o com a lógica.

Lacan elenca um sujeito da existência e uma essência que estão separados na medida em que é necessária a assimilação do primeiro ao segundo, através de um silogismo subjetivo. Se não é ao sujeito da existência que cabe o predicativo de humanidade, é porque ele não pode ser, em sua origem, chamado de humano. Poderíamos afirmar que se trata de um isso, de algo que não pode ser objetivável na esfera humana, pois a ela não pertence antes de sua assimilação à essência. Em última instância, por mais assimilado que possa ser, resiste de tal forma que não pode ser completamente subsumido, arrancado de sua existência inefável e jogado no campo da essência. Essa essência humana é caracterizada como radicalmente cultural, ou seja, o homem não recebe sua determinação de si mesmo enquanto pura existência, pois sua humanidade só pode ser determinada a partir de suas incidências neste campo, que é a cultura. É a cultura que possibilita esse sujeito da existência vir a ser, em vez de ficar reduzido a um nada.

Que silogismo é este que permite associar o sujeito da existência ao campo Outro da essência humana? Para abordá-lo, retomemos o artigo do ano anterior sobre o tempo lógico. O tempo lógico inicia com a apresentação de um problema de lógica, explicando como três presos conseguem sua liberdade a partir de um jogo no qual devem adivinhar a cor do disco preso em suas costas a partir de uma coleção de três círculos brancos e dois pretos.

A importância do artigo sobre o tempo lógico é reconhecida por Lacan na própria organização dos Escritos; ainda que seja de 1945, ele não está arrolado junto aos outros escritos seus contemporâneos. Pelo contrário, ele é colocado à parte, na terceira seção dos Escritos, junto com a Intervenção sobre a transferência, logo antes do pequeno artigo introdutório a respeito Do sujeito enfim em questão. Significaria que Lacan estaria localizando aí a antecipação da questão sobre o sujeito e sua determinação pela linguagem?

Deixemo-lo falar: "Possa ele [o artigo sobre o tempo lógico] ressoar uma nota justa entre o antes e o depois em que o situamos aqui, mesmo que demonstre que o depois se fazia de antecâmara para que o antes pudesse tomar seu lugar" (LACAN, 1966/1998d, p. 197). Antes, os escritos antecedentes centrados principalmente no estádio do espelho e a formação do eu; depois, o sujeito enfim em questão. Entre ambos, a "nota justa", um escrito digno de estabelecer a relação entre os dois pontos, a ponte entre o imaginário e o simbólico. E mais: $O$ tempo lógico não seria apenas um ponto de confluência, mas poderia ter seu lugar reconhecido somente quando colocado em perspectiva desse futuro, que serve, no fim das contas, de antecâmara para dar ao texto de 1945 seu verdadeiro valor. Afinal, tomado como está, sem enredá-lo em 
nenhum outro contexto, pareceria apenas um exercício de lógica recreativa se não fosse pelo cuidado com que Lacan aborda sua resolução. Porém, quando colocado em perspectiva com o questionamento do sujeito iniciado nos seminários, percebe-se o quanto tal questão já estava presente no espírito de Lacan, de uma forma embrionária, expressa nesse conflito entre a determinação do sujeito a partir de uma ordem exterior e sua possibilidade de ação frente a essa determinação massiva.

Primeiramente, precisamos identificar de que ordem exterior se trata, uma vez que, conforme vimos acima, interessa determinar como é possível, a partir de um conjunto, especificar um elemento singular. Existem três assujeitos anteriores a qualquer interação. Porém, neste "estado primordial", não há possibilidade de se determinar a singularidade de um ou de outro: é necessária a incidência de uma outra ordem - com seus discos, leis e, paradoxalmente, liberdade - que efetivamente marque esses assujeitos para que possa ocorrer o dito silogismo subjetivo, ou seja, para que, do coletivo, se possa diferenciar um elemento singular. Portanto, o coletivo de que se trata é o grupo de presos - "A coletividade já está integralmente representada na forma do sofisma, uma vez que se define como um grupo formado pelas relações recíprocas de um número definido de indivíduos" (LACAN, 1945/1998c, p. 212) - porém marcados por estes significantes impostos por um Outro: os círculos coloridos.

Tendo determinado qual é o coletivo em questão, antecipemos a conclusão do sofisma. Qual é ela? "Sou branco!" - ou seja, uma asserção subjetiva, como Lacan a denomina. No momento de concluir, premido pela pressa, não resta ao sujeito opção senão assumir para si a determinação que lhe foi dada - sob pena de perderse completamente nela. E, ao dizer de si, promove um movimento que ultrapassa simplesmente o sujeito lógico, mas refere-se ao sujeito pessoal, este que Lacan reconhece pelo pronome pessoal reto Je - o eu enquanto sujeito do inconsciente. Essa assunção diz respeito a uma subjetivação do significante que o marca, com a consequente separação do sujeito do resto da coletividade. "O [eu], sujeito da asserção conclusiva, isola-se por uma cadência de tempo lógico do outro, isto é, da relação de reciprocidade. Esse movimento de gênese lógica do [eu] por uma decantação de seu tempo lógico próprio é paralelo a seu nascimento psicológico" (LACAN, 1945/1998c, p. 208).

Essa conclusão que marca o nascimento do sujeito propriamente dito manifesta também esse ponto da subjetividade insolúvel à determinação pelo Outro através de um ato. No sofisma, o ato é concreto: há uma movimentação do sujeito em direção à saída e a enunciação, em alto e bom tom, de sua cor. Porém, como vimos acima sobre o complexo de desmame, tal ato não precisa se manifestar numa afirmação específica ou num comportamento: ele é ato enquanto parte deste nada que resta em torno da cadeia significante. Esse ato é a resposta do sujeito frente à demanda do Outro, que se traduz no sofisma como a pergunta por sua cor. O que é demandado ao sujeito transforma-se nele numa pergunta pelos desejos insondáveis desse Outro, que, antes da certeza de qualquer resposta, assume, pela pressa, determinada posição antecipatória.

Ao analisar o sofisma, Lacan denomina de "sujeito a concluir sobre si mesmo" o sujeito real que se coloca os questionamentos, e de "sujeitos refletidos" os outros dois sujeitos que servem de apoio para o raciocínio do sujeito real. Sujeitos refletidos, efetivamente, pois não passam, ao olho do sujeito real, de imagens às quais o sujeito em questão atribui pensamentos que sequer lhe ocorrem. Mas o sujeito real, que pode concluir sobre si, faz eco sobre o sujeito que surge posteriormente. Ao tomar para si a ordenação simbólica que o colocou em causa, pode dizer de si o seu lugar ao ser representado pelo significante.

A referência do sujeito ao outro constitui as premissas desse silogismo subjetivo, no instante de olhar e no tempo para compreender. Reduzido ao instante de olhar, tem-se apenas a forma impessoal do sujeito, não estando ele implicado de qualquer maneira. Pois ele parte da obviedade que, todavia, não é constatada na realidade: diante de dois pretos, é-se branco. Porém, o fato dessa conjunção rigorosamente lógica não existir de fato no sofisma não deixa de ter seus efeitos: é a premissa maior a partir da qual se deduz todo o resto do problema. 
No tempo para compreender, o sujeito fica reduzido em sua captura pelo outro, quando intui, no pensamento desses outros, ideias que poderiam the ocorrer, com base na premissa geral dada pelo instante de ver, mas que efetivamente não lhe ocorrem, pois tais hipóteses atribuídas ao outro se baseiam em dados errados. Porém, é nesse movimento, em que o outro só pode ser reconhecido como reflexo do próprio eu, que esse eu se determina a partir do reflexo que pode mirar no outro: tempo para compreender o que se é mas assumir tal ser reconhecido a partir desse jogo intersubjetivo exige um passo além, uma asserção apressada, antecipada.

A proposição original sobre o tempo lógico coloca-se como uma antecipação ainda preliminar da questão do sujeito; coloca o sujeito, enfim, em questão. Mas a fundamentação ainda incipiente de Lacan acerca da linguagem impede um desenvolvimento imediato do problema nos termos que podemos acompanhar nos primeiros seminários. A questão colocada precisará esperar alguns anos para amadurecer e ressurgir a partir do referencial lévi-straussiano da função simbólica.

\section{A LATÊNCIA DO SUJEITO E A RETOMADA DO NARCISISMO}

É a função imaginária que tampona a questão do sujeito emergente nesses escritos sobre a lógica subjetiva. Nos anos seguintes, o sujeito torna a aparecer apenas de forma tímida, voltando a ocupar o lugar central a constituição do eu a partir da identificação do sujeito com uma imago.

Ainda que os escritos restantes da década de 40 versem sobre o mesmo assunto - o estádio do espelho -, fazem-no centrando-se em aspectos diferenciados da teoria. A Proposição sobre a causalidade psíquica (LACAN, 1946/1998e) foca a questão da identificação e da imago como conceitos fundamentais para se pensar a formação do eu e das patologias psíquicas, em contraposição à teoria organodinamicista de Henri Ey; $A$ agressividade em psicanálise (LACAN, 1948/1998f) desenvolve as incidências agressivas decorrentes da constituição alienada da imago do corpo próprio e suas implicações para a prática da psicanálise; por fim, $O$ estádio do espelho como formador da função do eu (Je) (LACAN, 1949/1998g) faz um apanhado geral da teoria da formação do eu, expondo de forma resumida seus conceitos-chave. Uma retomada sistemática desses escritos pode ser conferida em nosso artigo sobre o imaginário nos escritos antecedentes de Lacan (KASZUBOWSKI; AGUIAR, 2015).

Neste olhar retrospectivo, os escritos sobre o imaginário retomam a tese de 1932: para que um saber sobre o sujeito possa aspirar a qualquer possibilidade de ser chamado de científico, é necessário se ater àqueles elementos objetivos de sua constituição. Se esse elemento é primeiramente localizado na imago, ela se mostra deficitária na medida em que está relacionada à formação do eu, permitindo que o sujeito mesmo continue fora de questão. Para questioná-lo efetivamente, Lacan delimitará outro elemento, o significante, na dependência do qual o sujeito se constitui. Ambos elementos - imago e significante - podem ser objetivados, terem sua origem localizada, respectivamente, no outro e no Outro.

Contudo, assim como em 1932, Lacan se questiona sobre a aparente autonomia do sujeito, que the permitia enunciar-se como um eu. Aqui, novamente fica demarcado um limite nessa abordagem objetivante: há algo impossível de ser abordado, seja pela via imaginária, seja pela via simbólica. Este aspecto, antes do início dos seminários sobre os escritos técnicos de Freud, já é denominado de um "real em nossos sujeitos" (LACAN, 1953/2005, p. 13). Mesmo sabendo que o conceito de real não permanece o mesmo no decorrer da obra de Lacan, retomemos o contexto no qual se insere tal citação: "Há na análise toda uma parte real em nossos sujeitos que nos escapa. Nem por isso ela escapava a Freud quando este tinha que lidar com cada um de seus pacientes; porém, naturalmente, estava igualmente fora de sua apreensão e alcance" (LACAN, $1953 / 2005$, p. 13). Em outras palavras, algo da ordem do sujeito que, ainda que perceptível em alguma medida, não pode ser abarcado por qualquer objetivação em imagens ou em palavras. 


\section{OS ÚLTIMOS PASSOS ANTES DO INÍCIO}

Porém, demos um passo grande demais e já nos situamos num momento pouco anterior à virada de 1953, com o Discurso de Roma. Os desenvolvimentos teóricos da década de 50 já apontam para sua inserção no estruturalismo. Tal inscrição fica particularmente evidente neste primeiro trabalho da década de 50, Introdução teórica às funções da psicanálise em criminologia (LACAN, 1950/1998h). A referência dada com relação ao simbólico é a de Marcel Mauss:

Reencontramos, pois, as fórmulas límpidas que a morte de Mauss traz de novo à luz de nossa atenção: as estruturas da sociedade são simbólicas; o indivíduo, na medida em que é normal, serve-se delas em condutas reais; na medida em que é psicopata, exprime-as por condutas simbólicas. [...] A manifestação psicopática pode revelar a estrutura da falha, mas essa estrutura só pode ser tomada por um elemento na exploração do conjunto. (LACAN, 1950/1998h, p. 134)

Ao associar a estrutura da sociedade ao simbolismo, Lacan se distancia da tentativa de encontrar, na ordem da imago, a correspondência à eficácia simbólica, como inicialmente ensaiado no artigo sobre o estádio do espelho (LACAN, 1949/1998g). Pelo contrário, torna-se necessário pensar a ordem do símbolo naquilo que determina a própria estrutura social. Tal estrutura pode ser evidenciada por sua relação estreita com a lei. Essa mudança de referencial força Lacan a teorizar que a instância do supereu se constitui, estranhamente, contemporânea ao próprio eu - o que acontece, em verdade, é um primeiro movimento que irá mais tarde demarcar a precedência da ordem simbólica sobre a determinação imaginária, posteriormente desenvolvida no esquema do buquê invertido (ZAFIROPOULOS, 2003).

É dessa relação com a lei que emerge uma interface possível entre a psicanálise e a criminologia: se é a lei que organiza a interação entre seres humanos, tanto no sentido de sua constituição quanto de sua responsabilidade frente ao grupo, coloca-se a questão sobre o crime, a transgressão da lei em sua face propriamente social - em sua punição - e individual - na responsabilidade e na culpa.

Uma primeira consideração dessa interface é a impossibilidade do crime e da psicopatologia encontrarem-se fora desta estrutura simbólica. Pelo contrário, como diz Lacan (1950/1998h), o comportamento "patológico" se exprime de forma tão mais simbólica que o comportamento "normal" que sua relação à estrutura é inegável. O que pontua novamente a questão: se o crime não pode ser compreendido senão como a própria realização da lei, que parte corresponde à responsabilidade do sujeito? Assim formulada, a questão nos é familiar, pois ela repete o mesmo problema que vem sido reiterado desde a tese: é possível sustentar algo de propriamente subjetivo para além da determinação massiva do sujeito pela ordem social?

Eis a resposta dada por Lacan: "A psicanálise soluciona um dilema da teoria criminológica: ao irrealizar o crime, ela não desumaniza o criminoso" (LACAN, 1950/1998h, p. 137). O ato criminoso é de origem eminentemente social, e não uma contravenção das normas cuja causa seria uma inadequação individual. Sua motivação não pode ser delimitada a essa instância que mais propriamente se afirma num inquérito, o eu. Pelo contrário, as motivações de um crime mostram sua face significativa ao se levar em conta outras instâncias do psiquismo, em especial o supereu, incorporação da lei simbólica na subjetividade. O verdadeiro sujeito no ato criminoso patológico não é o eu, mas o supereu, enquanto encarnação de uma lei despótica que pende o sujeito para a culpa e para a punição. Lacan "irrealiza" o crime ao situar o desviante como resultante de exigências sociais que coagem o sujeito a ocupar lugares conflitantes em sistema simbólicos distintos, acarretando então formas de compromisso interditadas no plano coletivo.

E por que não desumaniza o criminoso? Porque não coloca a origem do ato num lugar que estaria alhures à humanidade. O que implica, enfim, que, por mais que o eu não consiga se reconhecer sujeito de suas motivações - mas também sempre intimamente enodado na trama simbólica -, ainda assim o sujeito é responsável por sua posição na ordem simbólica, uma vez que ele a assume por meio da asserção subjetiva. 
Se este artigo sobre as relações entre criminologia e psicanálise é inaugural, na medida em que coloca a instância do supereu em foco para analisar sua relação com a estrutura social da lei, também o é ao dar importância ao isso. "Mais concreta é a noção com que nossa experiência completa a tópica psíquica do indivíduo - a do Isso -, porém, igualmente, quão mais difícil de apreender" (LACAN, 1950/1998h, p. 150). A importância dessa instância se revela na compulsão à repetição, que se mostra como pano de fundo dos comportamentos criminosos.

Em suma, Lacan abandona paulatinamente a importância dada à constituição imaginária do eu para pôr em evidência a própria divisão psíquica, exemplificada nesse acento dado ao supereu e ao isso, e suas relações a essa ordem que começa a despontar, a partir do diálogo com Lévi-Strauss: o simbólico. Contudo, se o estruturalismo começa a oferecer suas ferramentas para melhor abordar a determinação do sujeito, Lacan faz questão de notar que "a verdade que nos é dado reconhecer com o sujeito não pode ser reduzida à objetivação científica" (LACAN, 1950/1998h, p. 150), pois "a psicanálise [...] reivindica a autonomia de uma experiência irredutivelmente subjetiva" (LACAN, 1950/1998h, p. 148). No fim das contas, mesmo fazendo apelo ao simbólico para escrutinar a determinação objetiva e social do sujeito, Lacan pontua novamente a necessidade de se manter aspectos da subjetividade como inobjetiváveis.

A centralidade do conceito de sujeito mostra-se cada vez mais forte, a ponto de Lacan afirmar, no preâmbulo para os Escritos de seu artigo Intervenção sobre a transferência, escrito em 1966, que "estamos aqui a amestrar os ouvidos ao termo sujeito" (LACAN, 1966/1998d, p. 214). Colocando esta frase em seu contexto, pode-se concluir que, ao olhar para trás no caminho percorrido, Lacan verifica que, neste trabalho sobre a transferência, o sujeito enquanto conceito já estava presente, mas ainda não estava suficientemente definido. Para tanto, haveria que "amestrar os ouvidos", fazer com que eles se acostumassem com o termo e que, a partir dele, se pudesse redefinir a própria clínica, e, com isso, a teoria analítica.

\section{MOMENTO DE CONCLUIR}

A leitura retrospectiva aqui empreendida permite verificar o quanto dois dos principais predicados do sujeito - o fato de ele ser causado no campo do Outro, ou seja, ser determinado pela lógica do significante; e manter, em seu seio, um índice de indeterminação impossível de ser objetivado, uma falta em ser que constitui o desejo - estão presentes nos questionamentos de Lacan pelo menos desde sua tese de doutorado. Se a determinação do sujeito é primeiramente elaborada em sua captura por imagens num eu, posteriormente, o estruturalismo permite abordar mais especificamente como o sujeito é causado por uma ordem Outra, inicialmente associada ao símbolo, mais tarde precisada como significante. Ainda assim, permanece patente, já nos antecedentes lacanianos, a impossibilidade de se objetivar o sujeito, seja em termos de imagens ou em termos de significantes, restando um ponto de impossibilidade em torno do qual Lacan erige sua conceituação singular sobre o sujeito, na esteira da tradição metafísica, mas admitindo essa impossibilidade como um ponto central.

Recebido em: 10 de outubro de 2014. Aprovado em: 30 de janeiro de 2015.

\section{REFERÊNCIAS}

CABAS, A. G. O sujeito na psicanálise de Freud a Lacan: da questão do sujeito ao sujeito em questão. Rio de Janeiro: Zahar, 2009.

FREUD, S. A interpretação dos sonhos (1900). Imago: Rio de Janeiro, 2001.

Projeto para uma psicologia científica (1895). Rio de Janeiro: Imago, 1990. (Ed. standard brasileira das obras completas, 3. Ed., 1).

KASZUBOWSKI, E.; AGUIAR, F. (2015) O registro imaginário nos antecedentes lacanianos. Ágora, v. 18, n. 1. Rio de Janeiro: UFRJ, p. 85-100.

LACAN, J. A agressividade em psicanálise (1948). In Escritos. Rio de Janeiro: J. Zahar, $1998 \mathrm{f}$. 


\section{O conceito de sujeito nos antecedentes lacanianos: uma leitura em Nachträglichkeit}

As psicoses (1955-1956). Rio de Janeiro: Jorge Zahar, 1985a. (O seminário, 3).

De la psicosis paranoica en sus relaciones con la personalidad (1932). In: Lacan 2000. (1 CD ROM). Buenos Aires: RD Ediciones Eletrónicas, 2000.

. De nossos antecedentes (1966). In:

Escritos. Rio de Janeiro: J. Zahar, 1998a.

. Do sujeito enfim em questão (1966). In: Escritos. Rio de Janeiro: J. Zahar, 1998d. $1998 \mathrm{e}$

. Formulações sobre a causalidade psíquica (1946). In: Escritos. Rio de Janeiro: J. Zahar, Intervenção sobre a transferência (1951). In: Escritos. Rio de Janeiro: J. Zahar, 1998i.

Introdução teórica às funções da psicanálise em criminologia (1950). In: Escritos. Rio de Janeiro: J. Zahar, 1998h.

. Le nombre treize et la forme logique de la suspicion (1946). In: Pas-tout Lacan. Paris: École Lacanienne de Psychanalyse, 2009. Disponível em: <http://www.ecolelacanienne.net/documents/1946-00-00.doc>. Acesso em: 09 dez 2009. 2006.

Meu ensino, sua natureza e seus fins (1968). In: Meu ensino. Rio de Janeiro: J. Zahar,

. O estádio do espelho como formador da função do eu, tal como nos foi revelado na experiência analítica (1949). In: Escritos. Rio de Janeiro: J. Zahar, 1998g.

O eu na teoria de Freud e na técnica da psicanálise (1954-1955). Rio de Janeiro: Jorge Zahar, 1985c. (O seminário, 2). Zahar, 2005

O imaginário, o simbólico e o real (1953). In: Os Nomes-do-Pai. Rio de Janeiro: J.

Os complexos familiares (1938). Rio de Janeiro: Jorge Zahar, $1985 \mathrm{~b}$.

Os quatro conceitos fundamentais da psicanálise (1963-1964). Rio de Janeiro: Jorge Zahar, 1988j. (O seminário, 11).

O tempo lógico e a asserção da certeza antecipada (1945). In: Escritos. Rio de Janeiro: J. Zahar, 1998c. $1998 \mathrm{~b}$

Para-além do 'princípio de realidade' (1936). In: Escritos. Rio de Janeiro: J. Zahar, LAPLANCHE, J. Problematiques I: I'angoisse. 2. ed. Paris: Presses Universitaires de France, 1981 ZAFIROPOULOS, M. Lacan et Lévi-Strauss: ou le retour a Freud (1951 - 1957). Paris: PUF, 2008.

\section{Erikson Kaszubowski}

erikson.k@ufsc.br 